\title{
QUE ENXERGUEMOS O OUTRO SEM MEDO: A CONTRIBUIÇÃO WARATIANA PARA A EDUCAÇÃO EM DIREITOS HUMANOS
}

\author{
Renato Duro Dias* \\ Lucas Fernandes Pompeu*
}

\section{RESUMO}

O presente artigo discute a educação em direitos humanos tendo como base as contribuições de Luis Alberto Warat $(1977,1979,2003$, 2010). Este estudo de abordagem qualitativa se insere no campo das reflexões interdisciplinares, que procura analisar os sistemas jurídicos embasando-se, especialmente, nos campos da educação, da sociologia e da filosofia. A pesquisa se apropria de revisão de literatura para as categorias de análise destacadas. Trata-se de investigar a alteridade como uma capacidade de (des)construir o direito, a partir de uma educação alicerçada no cuidado com o outro, produzindo, assim, um novo direito, caracterizado por um espaço de transformação coletiva.

Palavras-chave: Alteridade; Direito; Educação em Direitos Humanos; Warat.

\section{WE SHALL SEE THE OTHER FEARLESSLY: THE WARANTIAN CONTRIBUTION FOR EDUCATION IN HUMAN RIGHTS}

\begin{abstract}
The present article discusses human rights education based on Luis Alberto Warat (1977, 1979, 2003, 2010) contributions. This qualitative approach study inserts itself in the interdisciplinary field of reflections aiming the analysis of juridical systems utilizing, specially, the fields of education, sociology and philosophy. The research uses literary reviews for the spotlighted categories of analyses. It is the investigation of otherness as a capability for (de)construction of law, going from a kind of education which is based on care for the other, thus, forming a new law marked by the idea of a collective change.
\end{abstract}

Keywords: Otherness; Right; Human Rights Education; Warat.

\section{INTRODUÇÃO}

O presente artigo discute a educação em direitos humanos tendo como base as contribuições de Warat (1977, 1979, 2003, 2010). Este estudo de abordagem qualitativa se insere no campo das reflexões interdisciplinares, que procura analisar os sistemas jurídicos,

\footnotetext{
* Vice-Reitor da Universidade Federal do Rio Grande - FURG. Professor da Faculdade de Direito e do Programa de Pós-Graduação em Direito - Mestrado em Direito e Justiça Social (FURG). Doutor em Educação (UFPel), com período na Universidade de Lisboa, Portugal. Vice-líder do Laboratório Imagens da Justiça - Grupo de Pesquisa (CNPq). Endereço: Av. Itália, $\mathrm{km} \mathrm{8,} \mathrm{Campus} \mathrm{Carreiros,} \mathrm{Rio} \mathrm{Grande,} \mathrm{RS,} \mathrm{Brasil.}$ CEP: 96203-900. E-mail: renatodurodias@ gmail.com.

* Advogado. Consultor Jurídico da Câmara Municipal do Rio Grande - RS. Mestrando em Direito e Justiça Social pela Universidade Federal do Rio Grande - FURG. Endereço: Rua Cristóvão Colombo, 240-B, Rio Grande, RS, Brasil. CEP: 96211-510. E-mail: pompeu.advocacia@hotmail.com.
} 
embasando-se, especialmente, nos campos da sociologia, da filosofia, da economia, da política e da educação. Entende-se, portanto, que uma análise interdisciplinar dos sistemas jurídicos necessita, obrigatoriamente, entender que

[...] o direito não é um objeto de conhecimento dado antecipadamente, a priori, que é externamente observado e descrito, mas deve ser construído a partir de diferentes interesses cognitivos, onde o pesquisador também faz parte daquilo que investiga (FARIÑAS DULCE, 1994, p. 1020, tradução nossa).

Muitas foram as reflexões do professor Warat para o campo do direito, talvez uma de suas mais importantes contribuições foi a de discutir os direitos humanos sob o ponto de vista da alteridade: "em nome de direitos humanos divinizados cinicamente, é toda a cultura da alteridade. É a guerra em estado permanente contra o outro. O diferente que deve ser exterminado para assegurar o êxito da Torre de Babel do Capitalismo das S.A. do dinheiro" (WARAT, 2010, p. 23).

A pesquisa se apropria de revisão de literatura para as categorias de análise destacadas. Trata-se de investigar a alteridade como uma capacidade de (des)construir o direito, a partir de uma educação alicerçada no cuidado com o outro, produzindo, assim, um novo direito, caracterizado por um espaço de transformação coletiva.

O artigo está organizado em três etapas. Numa primeira, discute-se conceitualmente alteridade como pressuposto ético (LÉVINAS, 2003) e suas implicações para o campo dos estudos jurídico-interdisciplinares. Na segunda etapa, abordam-se as interlocuções entre educação jurídica e alteridade, entendendo-as como categorias distintas, mas, fundamentalmente, entrelaçadas na possibilidade de construção de um sujeito-educando forjado em uma prática de escuta do outro. Ao final, procura-se extrair de algumas potentes obras de Warat possíveis contribuições teóricas para pensar a educação em direitos humanos, a alteridade e a democracia.

Como marca dos estudos exploratórios, esta pesquisa pretende reafirmar algumas premissas encartadas nos direitos humanos e que tanto emergiram das reflexões de Warat (2010), notadamente a proposta de um direito da alteridade construído a partir de uma sociedade mais justa, menos desigual e muito mais solidária. 


\section{ALTERIDADE COMO PRESSUPOSTO ÉTICO}

Por certo, não foi Emannuel Lévinas o primeiro filósofo a nos questionar sobre a alteridade e a fundamentalidade do outro (do rosto do outro) como pressuposto de um humanismo contemporâneo. No entanto, é a partir de Lévinas (2003) que se propicia entender a humanidade dependentemente relacionada à alteridade. Lévinas (2003) anuncia ao mundo a responsabilidade do humano com o outro.

De acordo com Lévinas, a sensibilização pelo outro, a abertura do eu para o rosto do outro possibilita a responsabilização pelo próximo e com isso o alcance do próprio sentido da sua própria vida.

Todo amor ou todo ódio do próximo, como atitude refletida, supõe esta vulnerabilidade prévia: misericórdia, "gemido de entranhas". Desde a sensibilidade, o sujeito é para o outro: substituição, responsabilidade, expiação. Mas responsabilidade que não assumi em momento algum, em nenhum presente. Nada é mais passivo do que este ser posto em causa anterior à minha liberdade, do que este ser posto em causa pré-original, do que esta franqueza. Passividade do vulnerável, condição (ou incondição) pela qual o ser se mostra criatura (LÉVINAS, 2003, p. 105).

O mérito de Lévinas (2003) é, sem dúvida, ter destacado a dimensão verdadeiramente universal desta preocupação, desta responsabilidade pelos outros. Ao trazer à tona as estruturas invariáveis dessa experiência do humano, a ética (e o sentido levinasiano dela), faz emergir o vasto campo da fenomenologia: lugar tão produtivo para o pensamento deste grande filósofo lituano.

Alguns diriam que o uso de o fato de Lévinas (2003) expressar o sentido dessa experiência em uma linguagem vinculada à religião, à fé e à própria palavra (invocando uma leitura cristã como método complementar a sua fenomenologia), não abala a potente neutralidade de suas análises, uma vez que não se baseiam em um testemunho de fé, mas sim, em um reflexo de seu sentido profundo de humanidade, ao revelar o caráter ético da essência do humano. 
É ali na alteridade que abriga infinitamente grande tempo num entretempo intransponível. O um é para o outro um ser que se desprende, sem se fazer contemporâneo do outro, sem poder colocar-se a seu lado numa síntese, expondo-se como tema, um--para-o-outro como um guardião-de-seu-irmão, como um responsável-pelo-outro (LÉVINAS, 2003, p. 16).

Neste sentido, Lévinas (2003) possibilita pensar a ética como filosofia primeira, sendo, simplesmente, o reconhecimento da gentileza como um traço essencial do ser humano. É só assim, a partir deste olhar ético/altero, que um novo humanismo pode ser estabelecido, um humanismo de um rosto que olha o outro e vê um irmão, alguém vulnerável ou uma vida precária (BUTLER, 2012), que deve ser respeitada e com quem é necessário colaborar para que a barbárie e a violência não nos desumanizem.

No campo da educação, o discurso sobre o outro e a reafirmação de um novo humanismo ganham múltiplo sentido, especialmente quando se analisa os contextos produtores de sentido no ensino do direito. Warat, nos anos 1980, denunciava a formação discursiva dos bacharéis em direito, constatado, em seus escritos, a ausência de uma práxis voltada para a alteridade e a transformação social.

De acordo com Warat (2003, 2010), as escolas de direito no Brasil se constituíram, ao longo de sua existência, em espaços de opressão, de intricadas relações de poder e de meras salas de aula reprodutoras de um ensino dogmático jurídico positivista ${ }^{1}$ e instrumental. Explica que essa situação teria sido gerida por um largo processo de profanação que foi transformando as situações que envolvem, cotidiana e cientificamente, os homens, em práticas coisificadas, práticas desprovidas de todo vínculo com as emoções, com os sentimentos:

[...] essa mágica conjunção dos acontecimentos com o poético que permite perceber, através das artes, do poético incorporado a vida, os elementos nobres da condição humana (a arte, o poético é visto pelos grandes poetas como essa dimensão do humano que permite resgatar das misérias humanas, de sua barbárie, essa dimensão do humano sagrado - inclusive a dignidade ou a nobreza na miséria humana) (WARAT, 2003, p. 12).

Ainda, nas palavras do autor:

\footnotetext{
${ }^{1}$ Para mais detalhamento ver Dias $(2014,2021)$ e Dias e Vianna (2016).
} 
Ao longo de vários séculos, nos últimos em especial, foi se configurando uma concepção normativista do Direito que foi outorgando identidade jurídica aos sujeitos da modernidade. Identidade cultural, que na posmodernidade, ou transmodernidade, entrou em crise profunda. A cultura jurídica institucionalizada, vítima dos exageros da razão instrumental (que reduziu os juristas a operadores), terminou reduzida a uma aplicação que se simula lógicomecânica-instrumental, mas sustentada ideologicamente por certas crenças que conservam institucionalmente seu valor, apesar de seu enorme descrédito dentro da Filosofia do Direito e da semiologia jurídica (WARAT, 2003, p. 12).

Tudo isso, explica Warat (2003), faz com que tanto no Direito, como agora na economia, exista um chamado "pensamento único". No primeiro espaço de práticas jurídicas, esse pensamento único foi eficaz para afirmar a identidade cultural dos juristas de uma maneira surpreendentemente solidificada, nos últimos três séculos. Na economia, as ideias em torno de um pensamento único são mais recentes, servem para afirmar ideologicamente as formas neoliberais da globalização.

Quando falava criticamente desse normativismo, alertava o professor, que não o fazia com a intenção de desqualificar o valor e a função social da lei na configuração do Estado e da convivência em sociedade. Enfatizava que a crítica se referia ao modo em que um conjunto de teorias e crenças de corte ideológico, em nome de uma determinada conceitualização e entendimento sobre o funcionamento das leis, foi construindo, ao longo de dois séculos, uma identidade jurídica para os sujeitos de Direito, de corte excessivamente normativista. Assim, fazendo girar todas as ideias da cultura em torno de uma exclusiva forma de entendimento sobre os mecanismos de produção, circulação e consumo dos sentidos da lei, seus vínculos com a justiça e sua força de resolução de conflitos. A crítica era necessária porque, segundo Warat (2003), a resolução jurídica dos conflitos terminou sendo colocada em último plano e quase esquecida, eis que passamos a privilegiar um sentido do Direito exclusivamente normativo. Os chamados operadores do Direito passaram a entender que a sua função era a de somente aplicar a lei ou administrar justiça, como se essas duas atividades fossem absolutamente independentes dos conflitos, a tal ponto que a maioria dos juristas de hoje, e a maioria das escolas de direito, perderam de vista que as leis foram criadas para prevenir conflitos. Chama à reflexão, e talvez seja o ponto central de seu pensamento, que as leis não têm identidade própria à margem dos conflitos.

Seguindo a sua explicação da situação atual do normativismo instaurado, afirmava que esta cultura-normativista outorgou identidade não somente à lei, mas também à cidadania 
e à democracia, que acabaram sendo representações fantasmáticas, abstrações sem referência à vida das pessoas, como os princípios gerais de Direito ou postulações programáticas como a do Estado de Direito, apelações vazias de vida, de emoção, de conflito humano.

\section{ENSINO, DIREITO E ALTERIDADE}

Recentemente, uma frase de Streck (2010) chocou o mundo acadêmico. Disse ele: "as faculdades de Direito nunca formaram tantos fascistas, como nos últimos anos" (STRECK, 2010, s/p). Trata-se de uma constatação triste de escutar, ver um sacerdote perder a fé na própria batina. Choca, em que pese seja verdade, e a verdade, por vezes, dói. Explicava ele que hoje possuímos um déficit constitucional, uma baixa constitucionalidade, eis que a nossa Carta - já não tão Magna para alguns - que tão belamente nos fala de índios, meio ambiente, educação, etc, é entendida por muitos como uma mera folha de papel, um mero conselho político, e não como norma. Cumprimos hoje só as normas que nos interessam, o que é danoso à democracia. Citou que a comunidade jurídica - e aí talvez incluindo a "A"cademia - é responsável por isso, eis que acabamos por não fazer os devidos constrangimentos quanto à situação. Não cuidamos, segundo ele, como deveríamos dos nossos cursos jurídicos, de onde saem agora os fascistas, em milhares.

Por mais paradoxal que seja, há uma enorme parte da comunidade jurídica que vocifera contra um suposto excesso de direitos previstos na Constituição, dizendo: temos direitos demais, o que prejudica um judiciário célere, uma sociedade combativa na luta contra a corrupção, etc. Se pensarmos, mais ou menos como que um mergulhador a reclamar do peso do tubo de oxigênio que carrega nas contas em pleno fundo do mar, dizendo que há oxigênio demais, fato que o prejudica ao mergulhar a metros e metros de profundidade.

Pois então: regimes totalitários são extremamente seletivos naqueles direitos que entendem como importante, e simplesmente não se importam com o outro, ou direitos dos outros, quando se entendem fora "do outro". Tudo, segundo eles, em nome de um "bem" maior. Se olharmos para de Hitler, por exemplo, seu ideal era uma sociedade limpa de raças. No de Lênin, o objetivo maior era uma sociedade limpa de classes. Guardadas as proporções expostas pela incomparável barbárie do nazismo; em ambos os casos, estava em jogo um 
universo esteticamente satisfatório, transparente, homogêneo livre de incertezas desesperadoras, de ambivalência (BAUMAN, 2011). Cruéis sim, mas com um propósito maior, segundo eles, uma missão quase que divina, que justifica todo o resto, como que a famosa frase de Maquiavel, nunca dita por Maquiavel: os fins justificam os meios.

Lenio, entretanto, ainda que indiretamente e talvez - vá saber - (in)consicientemente, citou uma situação que já há muito tempo vinha (e vem, como obra ad eternum), sendo alertada por Warat. Eram amigos, sendo que Lenio se declara fã de Warat ${ }^{2}$, a ponto de dizer que o velho professor mudou a sua vida. Sabe-se lá se no momento em que proferiu a chocante constatação pensou em Warat, mas ainda que não, indiretamente, remontou ao pensamento Waratiano. Se Lenio nos alerta que o ovo chocou, Warat há muito nos vinha alertando da existência do ovo, depois de uma vida inteira lutando contra a serpente.

Nunca fomos bem em gerir nossa relação com o outro, é algo um tanto quanto histórico. A Academia não tem culpa por ter um pé atrás quanto ao outro. Não, não se trata de uma questão dos últimos séculos, estamos falando de algo que vai um pouco mais além, uma dificuldade quase que entranhada em nosso DNA.

Cientificamente, as espécies que evoluíram de um determinado ancestral são agrupadas em gênero, e dentro do gênero, temos as espécies. Por exemplo, leopardos, leões a tigres são espécies diferentes do gênero Panthera, sendo que os biólogos nomeiam os organismos com um nome duplo latino, mais precisamente o gênero seguido da espécie (HARARI, 2020). Gênero + espécie. Leões, por exemplo, cientificamente são catalogados como Panthera leo, a espécie leo do gênero Panthera. Nós somos os Homo sapiens, somos a espécie sapiens (que quer dizer sábia. Sim, nos auto-catalogamos humildemente como sábios), do gênero Homo (homem) e, curiosamente, pertencíamos a uma família também (o que pode chocar a alguns que ainda hoje acham que o homem - pretensamente - sapiens é e sempre foi o centro do universo). Pertencíamos a uma família, éramos uma mera espécie de algo maior, fato que costumava ser um dos segredos mais bem guardados da história (HARARI, 2020).

Quando falamos em humano, cientificamente, estamos a nos referir a um animal pertencente ao gênero Homo, e antes, existiam várias outras espécies dentro desse gênero além da Homo sapiens. Os humanos da Europa e Ásia Ocidental deram origem ao Homo

\footnotetext{
${ }^{2}$ Disponível em: https://m.facebook.com/watch/?v=831817100988384\&_rdr Acesso em: 01 abr. 2021.
} 
neanderthalensis (homem do vale do neander); já na Ilha da Java, Indonésia, viveu, por exemplo, o Homo soloensis (homem do vale do solo). Há cerca de 70 mil anos, nós, os sapiens, cansamos da África Oriental e decidimos "sair para comprar cigarros", e nos espalhamos pela península arábica, e de lá, tomamos também a península arábica. Entretanto, quando chegamos nesses espaços, havia outros Homo - humanos ocupando estes territórios. O que aconteceu então? Será que nos adaptamos à diferença e passamos a viver bem em harmonia com o "outro", então descoberto? Não. A resposta nos vem pela "teoria da substituição", uma história de incompatibilidade, repulsa e genocídio. Sapiens e neandertais, por exemplo, tinham anatomias diferentes, provavelmente hábitos de acasalamento diferentes, odor corporal diferentes e, por isso, provavelmente, tinha pouco interesse sexual um pelo outro, o que não teria propiciado uma miscigenação. Daí, em função dessa incompatibilidade, explica a teoria, que o sapiens acabou por levar as outras espécies à extinção, eis que éramos melhores caçadores e coletores, graças a nossa tecnologia e habilidades.

Essa competição por recurso, provavelmente, desaguou em violência e genocídio. Como afirma Harari (2020, p. 26), “é bem possível que, quando os sapiens encontraram os neandertais, o resultado tenha sido a primeira e mais significativa campanha de limpeza étnica da história" e, se a culpa era dos sapiens ou não, "fato é que, tão logo eles chegavam a um novo local, a população nativa era extinta”. (HARARI, 2020, p. 27).

Mas, (in)(e)voluímos (a escolha fica a critério do leitor). Não precisamos mais brigar com espécies de nossa mesma família, hoje brigamos entre nós mesmo, aterrissando, na expressão cunhada por Bauman (2011, p. 259), na nossa “idade dos campos”. Hoje, após um século que ficou marcado por atrocidades, o paradigma da modernidade atualmente nos força a condicionar nossas vidas a uma determinada ideologia de mundo, que depois de um século carregado de "náuseas" e de uma humanidade demasiado manchada de sangue, afirma-se na presente quadra que se inaugura com a presença de uma mortífera globalização (WARAT, 2003, p. 2).

Como explica Warat (2003), trata-se, basicamente, de uma situação atual de mundo convertida em ideologia que esconde e disfarça suas próprias esperanças, mostrando-nos o quadro patético de uma humanidade que naufraga, que se desumaniza, e que, segundo ele, aprofunda a discriminação e a dominação, "multiplicando os campos de concentração" e transformando conceitos nobres em termos que escondem genocídios (WARAT, 2003, p. 2). 
Afirmava, ainda, que princípios e convicções que organizavam nossa maneira de viver acabaram por desentranhados de nosso meio social, gerando uma humanidade desencantada de si mesma, tudo fruto do último século de atrocidades.

Em suas palavras, "herdeiros de um desastre, temos que compreendê-lo criticamente, aprender com o que já passou para podermos recompor esperanças após o inventário da tragédia vivida" (WARAT, 2003, p. 3).

\section{AS CONTRIBUIÇÕES DE WARAT PARA UMA EDUCAÇÃO EM DIREITOS HUMANOS $^{3}$ - ALTERIDADE E DEMOCRACIA}

Warat dizia que toda a mudança em relação a esta desumanização atual passava pelo caminho da educação. Tornava-se urgente encontrar alguma terra firme. (Re)fundação, (re)umanização, (re)invenção do mundo e dos nossos vínculos com o outro (WARAT, 2003, p. 2). Reinventar, refundar, queria dizer, também, nas palavras do autor, poder ver-se a si mesmo desde o outro e para o outro, repensar tudo o que nos foi obrigado a pensar desde as escolas, academias, instituições, desde os lugares dos especialistas, "a digna voz das consciências acomodadas" como ele mesmo menciona (WARAT, 2003, p. 8), aquelas vozes que se acreditam estar na posse de um lugar de normalidade.

Devemos repensar tudo o que nos coloca em situações de discriminação, opressão, exclusão, seja no lugar do opressor ou do oprimido, do discriminado ou do discriminador. Devemos entender a noção de reinventar como a análise sincera das visões de mundo junto aos que não formam parte de todas essas certezas, de nosso mundo individual. Trata-se de um repensar, segundo o autor:

[...] de coração aberto e atento a tudo o que pode dar-se numa relação com o outro, desarmado de certezas ideológicas, com o coração aberto a tudo o que os vínculos com o outro pode brindar, procurando as palavras, os relatos, as ilusões que nos ajudem a olharmos a nós mesmos (WARAT, 2003, p. 8).

Ainda que com toda situação pós-traumática vivenciada no século XX, Warat (2003) nos convidava a ultrapassá-la, e o caminho, na sua visão, passava justamente pela

\footnotetext{
${ }^{3}$ Para a conceptualização de educação em direitos humanos ver Netto e Dias (2017).
} 
modificação em nossa instituição de ensino (que hoje formam fascistas). No meio dessa sucessão de mal estares e desencantos da história, no meio de um profundo sentimento de inumanidade e barbárie, vemo-nos na difícil tarefa de, segundo ele, repensar o valor da educação, dos direitos humanos e da cidadania.

Somente uma educação desde e para os direitos humanos e a cidadania poderia reinscrever os homens em suas esperanças primárias (WARAT, 2003, p. 7). Precisaríamos construir a ponte para uma nova humanidade com direito a ser sujeito legítimo da história, a qual precisaria construir para tanto, no plano das ideias e da prática política, um discurso de direitos humanos vistos como Direitos da Alteridade (natureza ou condição do que é outro, do que é distinto, situação, estado ou qualidade que se constitui através de relações de contraste, distinção, diferença).

Quanto ao ensino jurídico, Warat (2003) assegura que a cultura das cátedras quer que a gente, enquanto aluno, repita, memorize, faça um culto à memória, seja um aprendiz de erudito (que não é outra coisa que um burro com memória, segundo palavras do autor). Essa cultura de ensino jurídico, quer que nós sejamos para os outros. Ser para os outros significa, para ele, uma das maiores formas de alienação.

Explica que, quando um professor examina do modo em que normalmente o faz, está querendo que o aluno seja para ele. Basicamente um fale o que o outro quer ouvir. Ensina que “culturalmente ser para os outros é empanturrar-se de informações, de verdades e citá-las, repeti-las com precisão quando você é inquirido" (WARAT, 2003, p. 32). Os exames seriam concursos de memória e subserviência ao saber do professor. Publicamente, todos os professores concordam que é necessário ensinar a pensar, entretanto, no fundo, seguem comportando-se como "senhores feudais, não saem da Idade Média” (WARAT, 2003, p. 32).

Warat (2003) apostava numa disciplina surrealista, competente para fazer que seu coração prometa, se (com)prometa. Educar como uma forma de ajudar a disciplinar a alteridade (entendida como espaço de promessas recíprocas sem regras, moralismos, costumes, catálogos e rotinas) a produção da diferença na alteridade, com o outro, o "(com)promisso" na produção da diferença. Seria perigoso reduzir a Universidade a um conjunto de mecanismos e discussões por meio dos quais nos convoca, inclui e institui. A 
Universidade seria, para o autor, também, um conjunto de corpos que se encontram, que se (com)prometem. Adentrando mais a fundo em sua concepção de educação, educar seria:

[...] uma questão de alteridade, uma possibilidade de reviver criativamente minha relação com o outro, esse outro que pode ser uma palavra, um esconderijo para si mesmo, mas, fundamentalmente, esse outro com quem cada um de nós, hoje e sempre, nos encontramos porque essa relação com o outro é nossa pulsão de vida e de morte. Se o outro não estivesse aqui, no mundo, o que seria de nós? (WARAT, 2003, p. 35).

A educação, como ele a vê, seria uma atenção à diferença, bem como um processo de produção da diferença. Diferentes formas aprendendo a conviver mutuamente. Transformar a educação não seria outra coisa senão uma alteração do modo como vejo o outro, não requer outra coisa do que uma firme vontade de se arriscar a pensar de outro modo minha relação com os outros, que não deixa de ser uma forma de arriscar-se a pensar de outro modo a lógica instituída.

Não é difícil entender o porquê a cultura da cátedra esteja a formar tantos fascistas. $\mathrm{E}$ qual o impacto da constatação em nossa frágil democracia? Ora, primeiramente, precisamos compreender que, a superprodução de pessoas indiferentes ao "outro" acaba por minar o solo fértil da democracia. Democracia não é algo que surge e se apaga ao acaso, por vontade de determinadas pessoas em determinados momentos históricos. A democracia não é algo que foi inventado, como uma máquina a vapor (DAHL, 2016).

A democracia pode ser inventada e reinventada de maneira autônoma sempre que existem condições adequadas, condições favoráveis, um impulso que se desenvolve a partir do que Dahl (2016) chama de lógica da igualdade. Essa cultura de formalização do pensamento único alertada por Warat (2003), de um ensino que quer que sejamos para o outro, e não pelo outro (alteridade), mina o solo fértil onde brota e se mantem o pensamento democrático e, aos poucos, vai se formando um Estado oco, um faz de conta seletivo, onde se escolhe qual determinado direito deve ser cumprido e qual não, tudo em nome de um "bem maior", que não a observância da constituição como norma.

A democracia deixou de ser um anseio popular revolucionário do século XIX, tornando-se um slogan instituído no século XX e XXI, porém, completamente vaziou em seu conteúdo (SANTOS, 2002). Daí surgem diversos impasses em seu entendimento. Um estilo 
de globalização dominante, denominado de neoliberal disseminou uma concepção hegemônica, um entendimento formado do que seria a democracia. Na primeira metade do século XX, o debate em torno de se analisar se democracia era algo desejável ou não, acabou por ser resolvido a favor da desejabilidade. Entretanto, a proposta que se tornou hegemônica ao final de duas guerras mundiais, o conceito do que passamos a entender como democracia, implicou, por mais paradoxal que seja, em uma restrição a formas de participação e soberania, desaguando em uma concepção simplista de algo utilizado meramente como um procedimento eleitoral para formação de governos (SANTOS, 2002).

Democracia era entendida como algo simplesmente relacionado à forma (e não substância), sendo que o debate democrático se cingia à questão dos desenhos eleitorais, e o pluralismo era tido apenas como uma forma de incorporação partidária e disputas entre elites. Por mais paradoxal que seja, ao insistir-se nessa concepção hegemônica, "menos se consegue explicar o paradoxo da extensão da democracia ter trazido consigo uma enorme degradação das práticas democráticas" (SANTOS, 2002, p. 42).

Ao passo dessa concepção hegemônica do pós-guerra, restrita à legitimação de governos, surgiu também uma série de concepções alternativas, as quais são denominadas por Santos (2002) de contra-hegemônicas, pois não romperam propriamente com o sistema procedimental, mas vincularam este com forma de vida, entendendo a democracia como forma de aperfeiçoamento da convivência humana. E, dentre essa convivência, a intenção do reconhecimento da pluralidade humana.

Democracia seria uma gramática de organização da sociedade e da relação entre o Estado e sociedade. Ou seja, "a sociedade que acolhe e preserva a indeterminação em contraste notável com o totalitarismo que, edificando-se sob o signo da criação do novo homem, na realidade, agencia-se contra essa indeterminação" (LEFORT apud SANTOS, 2002, p. 51). Democracia, para a concepção contra-hegemônica é prática de reconhecimento da alteridade e a sua preservação, não só uma questão de forma como governos são constituídos. Ver o outro vai muito mais além do que questões partidárias e disponibilização de uma ou duas cadeiras em um parlamento.

Logo, o pensamento de Warat (2003) vai ao encontro dessas concepções contrahegemônicas, sendo que ajuda e dá o caminho para a formação humanista da democracia, 
aquela que vai muito além do entendimento de que, de quatro em quatro anos, apetarmos botões em uma urna eletrônica. Verificar se somos ou não somos uma país efetivamente democrático, e não um país de fascistas transvertidos, passa pela análise do quanto enxergamos o outro como pluralidade, e o quanto esse outro, em contraposição a mim que, para o outro, sou o outro, encontra-se inserido em nosso seio social, como pleno cidadão titular de direitos e obrigações.

\section{CONSIDERAÇÕES FINAIS}

A questão paradoxal das faculdades de Direito formarem hoje fascistas que bradam contra direitos e não enxergam o outro é (pelo menos parte de) uma emergente realidade, sendo que precisamos rumar, com urgência, para o caminho da alteridade.

É preciso que se redefina, nas cátedras, essa relação nossa com o outro, um modelo diferente de educação, já apontado por Warat em seus ensaios, uma educação social, na qual não caiba espaço somente para reles tolerância, mas sim de plena convivência, sem desconfianças. As faculdades de direito precisam de menos normativismo, menos formalismo, e mais humanismo. Deixar de ter um apego demasiado a normas padronizadas e regras de conduta, deixar de exigir que o aluno se enquadre em um modelo pré-formatado de ensino, onde o professor pergunta já aguardando aquilo que pretende escutar como resposta, a resposta certa e pré-moldada.

Talvez seja necessário que as graduações repensem seus currículos, a fim de entender que o ensino, em si, precisa ir além do utilitarismo. O ensino existe para a vida, e não a vida para o ensino. Cada um é cada um, e isso, ao contrário de gerar um caos, pode ser a base para a erradicação do pensamento fascista totalitário, onde não há espaço para a diferença existente. Talvez menos dogmas e mais direitos humanos, o que levaria ao entendimento que democracia implica pluralismo de ideias, autonomia e respeito às diferenças.

Somente a partir de uma educação alicerçada no cuidado com o outro, produzindo, assim, um novo direito desde as suas entranhas, caracterizado por um espaço de transformação coletiva, poder-se-á observar, de fato, a mudança em nosso contexto social. Reinventar, refundar, quer também dizer poder ver-se a si mesmo desde o outro e para o 
outro, repensar tudo o que nos foi obrigado a pensar desde as escolas, academias, instituições, desde os lugares dos especialistas, "a digna voz das consciências acomodadas" como ele mesmo menciona (WARAT, 2003, p. 8).

Precisamos entender a noção de reinventar como a análise sincera das visões de mundo junto aos que não formam parte de todas essas certezas, de nosso mundo individual. Trata-se de um repensar, segundo o autor:

[...] de coração aberto e atento a tudo o que pode dar-se numa relação com o outro, desarmado de certezas ideológicas, com o coração aberto a tudo o que os vínculos com o outro pode brindar, procurando as palavras, os relatos, as ilusões que nos ajudem a olharmos a nós mesmos (WARAT, 2003, p. 8).

A educação, como ele a via, deveria ser (e ainda deve) uma atenção à diferença, bem como um processo de produção da diferença. Um olhar atento ao outro. Transformar a educação não pode ser outra coisa senão uma alteração do modo como vejo o outro, não requer outra coisa do que uma firme vontade de arriscar a pensar de outro modo minha relação com os outros, que não deixa de ser uma forma de arriscar-se a pensar de outro modo a lógica instituída.

Para modificar a educação, é preciso voltar a olhar bem o que até agora enxergamos mal, voltar a olhar com paixão, voltar o olhar: "para a literatura, para o poético em geral e não para os dicionários ou outros lugares de erudição sem objetivos; olhar mais sobre o que é difícil de nominar, o inominado e ao que foi nominado como certeza ou verdade única" (WARAT, 2003, p. 36). Precisaríamos voltar a ver bem a diversidade para entender por que devemos abandonar as hostilidades do saber que reivindica o mesmo, o já dito desde sempre e que não revela nenhuma diversidade, pelo contrário, a discrimina para logo excluí-la.

Como pensava Warat (2003), os direitos humanos e a cidadania também têm que se metamorfosear, deixar de ser pensados a partir do já dito desde sempre. Os direitos humanos devem mudar para converter-se em direitos humanos da diversidade, da alteridade ou mesmo da cidadania, sem ser excludente da diversidade, genocida da diferença. A cidadania precisa considerar cidadãos aos que não respondem aos modelos já estabelecidos. Warat (2003) pensava que os direitos humanos e a cidadania devem mudar para começar a ser prática e 
discurso de hospitalidade com relação à diferença, daí a concepção de um olhar diferente - e central - para o tema da alteridade. Segundo ele, a educação tradicional, a baseada numa ideologia da escolaridade, seria hipocritamente tolerante impondo modelos onde, em nome da tolerância, "se excluem, se impõem atividades onde só podem unir-se o índio com o índio, o negro com o negro, o portador de deficiência física com outros portadores de necessidade especiais, o oriental com o oriental, os latino-americanos só entre si” (WARAT, 2003, p. 37). Tenhamos em mente a lição de que uma educação que enxerga o outro como problema começa a ser discriminatória. Os direitos humanos e a cidadania não podem ser discursos e práticas de ordenação/controle, mas sim, acima de tudo, de uma atenção voltada constantemente para a busca da alteridade. A busca - com carinho - pelo outro, entendendo-o não como parte da minha história, mas como uma história em si mesmo.

\section{REFERÊNCIAS}

BAUMAN, Zygmund. Vida em fragmentos: sobre ética pós-moderna. Rio de Janeiro, Zahar, 2011.

BRUM, Amanda Netto e DIAS, Renato Duro. (Re)significando o discurso dos Direitos Humanos: um diálogo a partir da educação em e para os Direitos Humanos. Revista Quaestio Iuris, UERJ, v. 10, p. 2396-2412, 2017. Disponível em: https://www.epublicacoes.uerj.br/index.php/quaestioiuris/article/view/25690 Acesso em 02 abr. 2021.

DAHL, Robert Alan. Sobre a Democracia. Tradução de Beatriz Sidou. 2. ed. Brasília. Editora Universidade de Brasília, 2016.

DIAS, Renato Duro. Relações de poder e controle no currículo do curso de direito da FURG. Tese de Doutorado. Programa de Pós-Graduação em Educação, Universidade Federal de Pelotas. Pelotas, UFPEL, 2014. Disponível em:

http://repositorio.ufpel.edu.br:8080/bitstream/prefix/3348/1/DIAS\%2C\%20Renato\%20Duro.p df Acesso em 29 mar. 2021.

DIAS, Renato Duro. Extensão universitária nos cursos de Graduação em Direito. Revista Quaestio Iuris, UERJ, v. 14, p. 21-39, 2021. Disponível em: https://www.epublicacoes.uerj.br/index.php/quaestioiuris/article/view/42892 Acesso em: 02 abr. 2021.

DIAS, Renato Duro e Vianna, Jonas M. C. Interdisciplinaridade e currículo do curso de direito: um estudo de caso. Revista Quaestio Iuris, UERJ v. 9, p. 1389-1413, 2016. Disponível em: https://www.e-publicacoes.uerj.br/index.php/quaestioiuris/article/view/20173 Acesso em: 01 abr. 2021. 
FARIÑAS DULCE, María José. Sociología del Derecho versus análisis sociológico del Derecho. Doxa, Alicante, n. 15-16, p. 1013-1023, 1994.

HARARI, Yuval Noah. Sapiens: Uma breve história da humanidade. 51. ed. Porto Alegre, RS: L\&M, 2020.

LÉVINAS, Emannuel. O humanismo do outro homem. 3. ed. Petrópolis-RJ: Vozes, 2009.

SANTOS, Boaventura de Souza. Democratizar a Democracia: os Caminhos da Democracia Participativa. Rio de Janeiro. Editora Civilização Brasileira, 2002.

STRECK, Lenio. A importância da educação, ciência e tecnologia para um projeto de desenvolvimento. Palestra. [S. L.], 2020. Disponível em: http://www.ihu.unisinos.br/78noticias/602737-as-faculdades-de-direito-nunca-formaram-tantos-fascistas-como-nos-ultimosanos-afirma-lenio-streck Acesso em: 10 nov. 2020.

WARAT, Luis Alberto. A rua grita Dionísio! Direitos humanos da alteridade, surrealismo e cartografia. Rio de Janeiro: Lumen Juris, 2010.

WARAT, Luis Alberto. Educação, Direitos Humanos, cidadania e exclusão social: fundamentos preliminares para uma tentativa de refundação. [S. L.], 2003. Disponível em:

http://dominiopublico.mec.gov.br/pesquisa/DetalheObraForm.do?select_action\&amp;co_obra $=18585$. Acesso em: 10 nov. 2020.

WARAT, Luis Alberto. Semiótica y Derecho. Buenos Aires: Editorial Eikon, 1972.

WARAT, Luis Alberto; CUNHA, Rosa Maria Cardoso. Ensino e Saber Jurídico. RJ: Eldorado, 1977.

WARAT, Luis Alberto. A Definição Jurídica: suas técnicas e texto programado. Porto Alegre: Atrium, 1977.

WARAT, Luis Alberto. Mitos e Teorias na Interpretação da Lei. Porto Alegre: Síntese, 1979.

WARAT, Luis Alberto. A Pureza do Poder. Florianópolis: Editora da UFSC, 1983.

WARAT, Luiz Alberto. Introdução Geral ao Direito. Porto Alegre: Sérgio Fabris, 1994.

WARAT, Luis Alberto. Por quien Cantan Las Sirenas. Chapecó: UNOESC/CPGD, 1996.

WARAT, Luis Alberto. A Rua Grita Dionísio! Rio de Janeiro: Lumen Juris, 2010. 